\title{
Assessment of Public Discernment on Factors Influencing the Declined Gross Domestic Product of India
}

\author{
BonamSivakumar, KoppalaVenugopal, D. Vishnu Murty
}

\begin{abstract}
Gross Domestic Product of India being discouraging at present with declining trend, has paved the way to find out the economic reasons through highly established literature, observations and common sense applications should be perceived by public in line with which factor influences the most backed by rationality. There have been certain factors such as improper execution of demonetisation policy, initial stoppage of money flow through GST, decreased consumption of goods, unavailability of banking credits and loans, diminished investments, discontinuous government overheads, declined exports and lowering Industrialisation have been found imperative to influence on GDP. Having the objective to identify the knowledge and assess the perception of the public on the factors, the study went through a method mix of descriptive research, quantitative approach and cross sectional design with a standard questionnaire intended to get the responses from the different people from Srikakulam District of Andhra Pradesh. Multiple Regression Analysis was used to analyse the weightage of each independent factor on the decline of GDP. Conclusion on the level of knowledge and perception on the factors have been established.
\end{abstract}

Key Words: GDP, Economic Growth Factors, Srikakulam District, Public perception

\section{INTRODUCTION}

Gross Domestic Product being goods as well as services with its wholesome market value produced in a nation at a particular time period, measures the monetary value bought by the final user. It measures the extent of an economy and overall development or deterioration in the nation's economy.

India's GDP growth decelerated to a more than five-year low at $5 \%$ in the June quarter of $2019-20$, against $5.8 \%$ in the March quarter. This is way below analysts' expectations of economic growth at $5.7 \%$ in the June quarter.

Growth of manufacturing sector almost downfalls at $0.6 \%$ in the June, against 3.1\% in the March in 2019 and among services sectors, only trade, hotels, communication segment have developed quicker in the June at $7.1 \%$, in comparison with March growth of $6 \%$. Both financial services with $5.9 \%$ and public administration services with $8.5 \%$ braked in June. The only sector that proceeded with a healthy growth is electricity, rising at $8.6 \%$ in the June, from $4.3 \%$ in the preceding quarter.

Revised Manuscript Received on December 30, 2019.

Dr BonamSivakumar, Professor , Department of MBA, Aditya Institute of Technology and Management, Tekkali, Srikakulam, AP, India.

Dr.KoppalaVenugopal, Professor \& HOD, Department of MBA, Aditya Institute of Technology and Management, Tekkali, Srikakulam, AP, India

Dr. D. Vishnu Murty, Dean and Professor, Aditya Institute of Technology and Management, Tekkali, Srikakulam, AP, India
As observed the statistics of comparison with previous years, the GDP has fallen down drastically and assumed to be much weaker in coming time since the conditions and factors influencing GDP are quite not prospective as on today. Negative forces are exhilarating in expectation with alarming signs in future for the factors have been found noncooperative to the conditions prevailing in India.

Though there have been some reasons from the policy makers relating to the governance, much impact shown by particular issues gathered from common sense applications, literature and observations influence significantly on GDP, Specificity of Indian circumstances at present have established the factors with their negative effect i.e. improper execution of demonetisation policy, initial stoppage of money flow through GST, decreased consumption of goods, unavailability of banking credits and loans, diminished investments, discontinuous government overheads, declined Exports and lowering Industrialisation.

People are talking everywhere about this drastic crisis of GDP which never fallen down as such. Generalised ideology of any common man about country's prosperity is well conveyed and defined by GDP. In recent news, the debate on this has been dynamically frequent and emotional also. Researchers intended to find the importance of the people's opinion on which factor impacts much on GDP and the reasons known by them were to be established.

The gap in the research is found significantly since the topic is spectacle with recent dynamics at the standpoint of total variables which are to be nurtured well with the opinion of the public. The survey in Srikakulam district in Andhra Pradesh has been taken up to identify the level of knowledge and understanding about the problem since the district is an underdeveloped, wherein many rural and semiurban places exist. Their enlightened ideology on every factor was analysed with statistical quantification and the weightage given to every factor through Multiple Regression Analysis may convey the message to the authorities for the benefit of economic growth through modifying policy making to honour the people's verdict.

\section{RESEARCH OBJECTIVES}

The research in the study area of Srikakulam District, Andhra Pradesh, aims at

1. Identification of knowledge of public on the factors influencing Gross Domestic Product

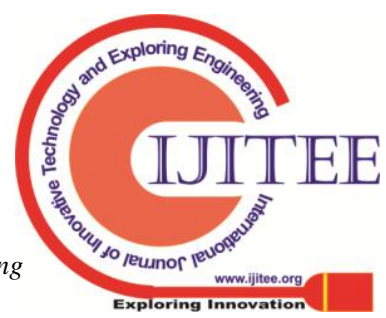




\section{Assessment of Public Discernment on Factors Influencing the Declined Gross Domestic Product of India}

2. Assessment of level and strength of factors' influence on Gross Domestic Product

3. Offering recommendations for the authorities to strengthen the economy through the decisions made by the respondents

\section{HYPOTHESES}

H1: Demonetisation policy, in the way of eradication of currency notes and scarcity has high influence on the declined GDP of India.

H2: Implementation of GST which caused trade disturbances has high influence on the declined GDP of India.

H3: Decreased Consumption of goods has high influence on the declined GDP of India.

H4: Deterioration in banking credits and loans has high influence on the declined GDP of India.

H5: Decrease in investments has high influence on the declined GDP of India.

H6: Uncontrolled government overheads has high influence on the declined GDP of India.

H7: Decrease in exports has high influence on the declined GDP of India.

H8: Slowdown Industrialisation has high influence on the declined GDP of India.

\section{RELATED LITERATURE}

\subsection{Demonetisation policy}

Demonetisation of bank notes categorically for 500 and 1000 rupees was announced on 8th November 2016 and issuance of new notes simultaneously to restrain the illegal operations of transactions. Though the initial the support from bankers and international critics were established, the planning with poor execution led to many protests against government. However there were mixed attitudes from intellectuals and common people where positive ideas stated by a very few like JagdishBhagwati, Indian-American economist and many such asAmartyaSen, KaushikBasu, PronabSen, PrabhatPatnaik, T. N. Ninan and Paul Krugman specified as an unsuccessful attempt and major mistake.

Many other felt that demonetisation policy had led to weakening growth rate because of the deficiency of notes which caused to dwindled consumption of goods. This situation there by proceeded to less production which routed to drastic losses and lessening employment opportunities. There was a major negative influence on the micro, small and medium enterprises also.

\subsection{Goods and Services Tax (GST)}

Goods and Services Tax being a major reform for taxation in order to eradicate the flowing effect of transaction tax and make products and services available at lower prices was implemented. Many such as DBS bank proclaimed that this would proceed to inflation rise initially for a year and thereafter would give positive results.

In a report, DBS bank noted that initially, GST will lead to the rise in inflation rate which will remain for a year but after that GST will affect positively on the economy. In addition to positive elements in GST, the initial and instant development was drastic in line with the adverse effect on economy.
The policy created some important disturbances in obtaining licences, submitting returns, and paying taxes due to lack of complete knowledge on how to manage it Business people being unhabituated to this policy, dragged on the payments of taxes and returns. This has made the revenue delayed for the government and paved the way for decline in GDP.

\subsection{Consumption of goods}

Despite the go-slow in manufacturing and construction sectors, the precipitous deterioration in consumption has become the foremost reason which accounted sharp fall from $7.2 \%$ in the March 2019 to $3.1 \%$ in the June 2019 shown as withered by $71 \%$. The statistics displayed that the growth of economy is highly depended on the consumption of consumables, specifically FMCG and automobile sector sales have been deprived through their undermined status of demand. The pace of transactions moving from one to another is an indication of revenue gained by the government whereas the sales being stagnant is always an alarm for the GDP growth. The status of the country is such now a days.

\subsection{Banking credits and loans}

Banking sector that provides credits and loans for European countries does not disturb inflation but, affects economic growth (SunaKorkmaz, 2015).

Prosperity of financial markets is a forerunner for the economy of any country. Financial freedom brings financial deepening which play a vital role in moving created funds to real sector and contributing to economic growth (SunaKorkmaz, 2015).

A long term co-integration relationship occurs in the manufacturing sector between credit and GDP which is also shown in overall GDP and credit data during the early period of economic growth of India (Charan Singh et al. 2016).

In recent time, the banks have started reducing credits and loans which leads the entrepreneurs and others to look at NBFCs (Non-Banking Financial Companies) but after the September 2018 crisis, there has been a wealth deficit and banks reduced providing loans to NBFCs. Availability of funds have been directed to the lowest consumption and thereby the growth is decreased.

\subsection{Investments}

Investments from several sources play a domineering role in improving economic conditions and GDP as well. A good number of corporates and business people invested in view of the previous GDP rate of $8 \%$ would be prospective. But the conditions prevailing with respect to the severe decline of GDP at present, most of them are neither gained profits from the past investments nor interested to proceed to new investments for the reason that their aspirations on the returns are ambiguous enough to generate profits. This could be one of the reasons to decline the growth of our economy. 


\subsection{Government overheads}

Ben EtimUdoh et al (2018) recognised that government outflows have a positive influence on community services and suggested that the most efficacious way to exhibit progress would be through adequate outflow via capital outflow and a reduction in recurring outflow in all divisions of the economy which is highly advisable for the growth of nation.

Samson, (2013) observed out of his Vector Error Correction and Granger Causality Model that administrative outflow and economic movement is substituted by GDP that shows the negative and significant association between outflow of government and industrial sector.

Robinson et al (2014) examined the positive association between government outflow and economic evolution with respect to the public debt expenditure, expenditure on health, and Education which will increase both foreign and local investments.

Overheads of the both central and state governments should be controlled by the money deficit by reducing the expenses but quite contrary to this generalisation the governments have been habituated to spend more and expected to be uncontrolled further in the coming years. It is alarming that the revenues of the governments being decreased considerably, the expenditure increase will lead to drastic deficit in the budget which is evident in these six months. Focus on this could generate some solution but the accustomed bureaucratic practices may or may not allow the reforms of slowing down expenses.

\subsection{Exports}

Mohammad Rafiqul Islam and MohaiminulHaque (2018) stated that developing country's exports has a significant influence and impact on the economic growth and thereby becomes an additional value to the growth of its GDP.

Instincts coming from GDP have influence on exports, whereas the instincts generated from exports show insignificant impact on GDP (MukherjiRonit and PandeyDivya 2014).

Uncontrollable imports of the gold being needless should be focussed by the Indian government since the increase in imports shows high significance on the decline on GDP (Venugopal K, 2016)

It has been found that the exports are diminished in the recent time and the decline of $8.57 \%$ in September 2019 notifies the condition of the exports status. The causes may be the slowdown of global market economy, inconsistencies between countries and business war between US and China which influences Indian export market significantly. At the same time, deterioration in imports are encouraging enough to blame not more on the responsibility of GDP downfall. But, the exports being developed will make the economy stronger as an added value to grade up the growth rate.

\subsection{Industrialisation}

Adenomon, M and Oyejola, B. A (2013) innumerable innovative practices were afforded by agriculture and other industrial sectors, but the maximum results achieved by agriculture sector which in fact has to be recommended for promotional incentives such as schemes and infrastructure facilities for the benefit of farmers. They also suggested new approaches to rejuvenate and strengthen back the industrial sector.

While investigating the causal relationship among the supply of electricity, industrialisation and economic growth by Udah (2010), all were found significantly effective and influential. Besides, capital employed was also considered weighty.

The indication of diminishing spirit developed by industrialists and the government is well experienced by us these days and the productivity has been found significantly decreased for two months. Specifically the manufacturing sector inclined up and down in between $2.8 \%$ and $4.4 \%$ durng 2014-15 and 2018-19 respectively. Manufacturing being domineering to turn the growth into two digits percentage, the industry should have a strategic view. But, there has been a silence which makes the GDP pulling back because of the FMCG products are found decreased in sales.

Conceptual Framework

Facts finding from the literature, researcher have drawn specified factors influencing declined GDP and the conceptual framework is portrayed as follows.

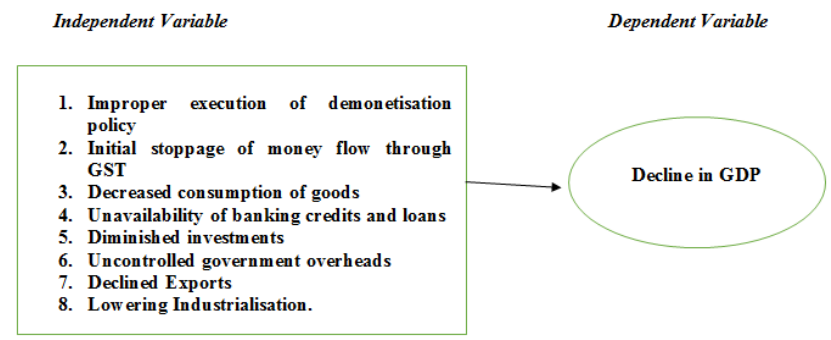

\section{Figure: Conceptual Framework (Source: Researchers review)}

\section{METHOD MIX}

Srikakulam being the geographical study area treated as one of the underdeveloped districts in Andhra Pradesh borders the state of Odisha, has different and distinguished shades of demographical consensus with admirable attributes of political and economic knowledge and related communication skills

Research design was amalgamated with descriptive type as most of the factors in general have been covered by the same design. The study went through cross-sectional where the data was collected at a sole instant and examined to get findings. To discourse the objectives stated, a standard questionnaire alone was distributed as data congregation method. Quantitative method was applied in this research to analyse data collected from different respondents.

The target population of the study was the public from different domain who are highly interested and knowledgeable towards economic factors influencing GDP. So the population size is infinitive and the appropriate sampling method used to select respondents was convenience sampling method of non-probability technique. The study determined the size of 260 in line with the

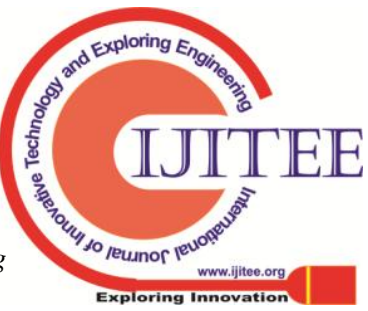




\section{Assessment of Public Discernment on Factors Influencing the Declined Gross Domestic Product of India}

constraints and limitations by following the quality assurance mechanisms and ethical considerations.

\section{ANALYSIS AND INTERPRETATION\& RESULTS}

Table 5.1 Model Summary

\begin{tabular}{|l|l|l|l|l|}
\hline Model & $\mathrm{R}$ & $\begin{array}{l}\mathrm{R} \\
\text { Square }\end{array}$ & $\begin{array}{l}\text { Adjusted } \\
\text { Square }\end{array}$ & $\begin{array}{l}\text { Std. Error of the } \\
\text { Estimate }\end{array}$ \\
\hline 1 & $.302^{\mathrm{a}}$ & .091 & .044 & 1.006 \\
\hline
\end{tabular}

Predictors: (Constant), FD1, FD2, FD3, FD4, FD5, FD6, FD7, FD8

As shown in table 5.1, R Square value is 0.09 , it means all the influencing variables are contributing 9.1 per cent in the decline of GDP. The remaining 90.9 is being contributed by other unknown variables.

\subsection{ANOVAa}

\begin{tabular}{|l|l|l|l|l|l|}
\hline Model & $\begin{array}{l}\text { Sum of } \\
\text { Squares }\end{array}$ & $\begin{array}{l}\text { Mean } \\
\text { Square }\end{array}$ & F & Sig. \\
\hline
\end{tabular}

\begin{tabular}{|l|l|l|l|l|l|}
\hline \multicolumn{1}{|c|}{ Regression } & 23.255 & 12 & 1.938 & 1.917 & $.033^{\mathrm{b}}$ \\
1 Residual & 231.559 & 229 & 1.011 & & \\
$\quad$ Total & 254.814 & 241 & & & \\
\hline
\end{tabular}

a. Dependent Variable: Decline in GDP

b. Predictors: (Constant), FD1, FD2, FD3, FD4, FD5, FD6, FD7, FD8

Table 1.2 shows the relationship between the decline of GDP and independent variables (FD1, FD2, FD3, FD4, FD5, FD6, FD7 and FD8). The F value between dependant variable and predictors is 1.917 , and the significant value is 0.033 which is significant at 0.05 level. On the other hand, we can also conclude whether there is one level in items' increase, there will be the increase of 231.559 in influencing economic factors.

Thus, it can be interpreted that the predictors of influencing economic factors have a significant influence on the decline in GDP.

Table 5.3: Coefficients ${ }^{\mathrm{a}}$

\begin{tabular}{|c|c|c|c|c|c|}
\hline \multirow[t]{2}{*}{ Model } & \multicolumn{2}{|c|}{$\begin{array}{l}\text { Unstandardized } \\
\text { Coefficients }\end{array}$} & \multirow{2}{*}{$\begin{array}{l}\text { Standardized } \\
\text { Coefficients } \\
\text { Beta }\end{array}$} & \multirow[t]{2}{*}{$\mathrm{T}$} & \multirow[t]{2}{*}{ Sig. } \\
\hline & $\mathrm{B}$ & Std. Error & & & \\
\hline (Constant) & -.472 & .693 & & -.682 & .496 \\
\hline $\begin{array}{l}\text { FD1. Improper execution of demonetisation } \\
\text { policy }\end{array}$ & .096 & .106 & .061 & .906 & .366 \\
\hline $\begin{array}{l}\text { FD2. Initial scarcity of money flow through } \\
\text { GST }\end{array}$ & .106 & .111 & .064 & .951 & .343 \\
\hline FD3. Decreased consumption of goods & .069 & .099 & .052 & .693 & .489 \\
\hline $\begin{array}{l}\text { FD4. Unavailability of banking credits and } \\
\text { loans }\end{array}$ & .017 & .102 & .013 & .167 & .867 \\
\hline FD5. Diminished investments & .216 & .104 & .153 & 2.069 & .040 \\
\hline FD6. Discontinuous government overheads & -.113 & .094 & -.097 & -1.211 & .227 \\
\hline FD7. Declined Exports & .183 & .086 & .147 & 2.114 & .036 \\
\hline FD8. Lowering Industrialisation & .121 & .097 & .086 & 1.242 & .215 \\
\hline
\end{tabular}

a. Dependent Variable: Decline of GDP

As per the Coefficients retrieved from table 3.7, the formula can be as follows

$\mathrm{y}=\alpha+\beta 1 \times 1+\beta 2 \times 2+\beta 3 \times 3+\beta 4 \times 4+\beta 5 \times 5+\beta 6 \times 6+\beta 7$

$\mathrm{x} 7+\beta 8 \mathrm{x} 8$

Where

$\mathrm{y}=$ Dependant variable

$\mathrm{x}=$ Independent variable

$\alpha=$ Intercept

$\beta=$ Estimate

FD: Factors for the Decline in GDP

Execution of information in the equation is
Decline in GDP (Dependable Variable $)=9.1+(.061)$ FD $1+(.064) \mathrm{FD} 2+(.052) \mathrm{FD} 3+(.013) \mathrm{FD} 4+(.153) \mathrm{FD} 5+$ $(-.097)$ FD $6+(.147)$ FD $7+(.086)$ FD 8 
As shown in the equation drawn with the weightages from the table 5.3, Decline of GDP with respect to FD1 (Improper execution of demonetisation policy) is 9.161 $(9.1+0.061)$; if IFC1 increases by one unit, the overall performance is increased by 9.161. Likewise if the increased by one unit, the profit of the business unit is increased for FD 2 (Initial scarcity of money flow through GST) by 9.164; FD3 (Decreased consumption of goods) by 9.152; FD 4 (Unavailability of banking credits and loans) by 9.113 ; FD 5 (Diminished investments) by 9.253 ; FD (Declined Exports) by $9.247 ; \quad$ FD 8 (Lowering Industrialisation) by 9.186 .

Hypotheses testing:

H1: Demonetisation policy, in the way of eradication of currency notes and scarcity has high influence on the declined GDP of India.

The weightage of the factor improper execution of demonetisation policy is 9.161 which is moderately acceptable since the sufferers of the policy are expanded to many places. Hence the hypothesis is accepted

H2: Implementation of GST which caused trade disturbances has high influence on the declined GDP of India.

The weightage of the factor Initial scarcity of money flow through GST is 9.164 which is moderately acceptable, so, it can be understood that most of the people have acquainted with the knowledge on GST and its implications. Hence the hypothesis is accepted

H3: Decreased Consumption of goods has high influence on the declined GDP of India.

The weightage of the factor decreased consumption of goods is 9.152 which is moderately acceptable since the consumption on FMCG products are familiar to the public. Hence the hypothesis is accepted

H4: Deterioration in banking credits and loans has high influence on the declined GDP of India.

The weightage of the factor Unavailability of banking credits and loans is 9.113 which is lower than other factors since the relationship between bank credits \& loans and GDP is not well understood by the public. Hence the hypothesis is rejected.

H5: Decrease in investments has high influence on the declined GDP of India.

The weightage of the factor diminished investments is 9.253 which is the highest influencing factor since the public feel that the investments on the business and developmental activities influences more on GDP. Moreover the significant value is 0.04 which is less than $\mathrm{p}$ value i.e. 0.5. Hence the hypothesis is highly accepted.

H6: Uncontrolled government overheads has high influence on the declined GDP of India.

The weightage of the factor uncontrolled government overheads is 9.003 which is the lowest influencing factor since the public strongly assume that the government expenditure which are mandatory and regularly proceeded do not influence on GDP. Hence the hypothesis is highly rejected.

H7: Decrease in exports has high influence on the declined GDP of India. predictors FD2, FD3, FD4, FD5, FD6, FD7 and FD8 are 6 (Discontinuous government overheads) by 9.003 ; FD 7

The weightage of the factor decrease in exports is 9.247 which is higher than other factors since the export value is well understood by the public who believe that the exports influence GDP positively. Moreover the significant value is 0.036 which is less than $\mathrm{p}$ value i.e. 0.5. Hence the hypothesis is highly accepted.

H8: Slowdown in Industrialisation has high influence on the declined GDP of India.

The weightage of the factor slowdown in industrialisation is 9.186 which is moderately higher than other factors since the importance of industrialisation is reciprocated by public and influence on GDP growth. Hence the hypothesis is accepted.

\section{CONCLUSIONS}

Diminished investments is considered to be the most influencing factor which has been reciprocated well by the public in line with the positive perception since the investments that have been drastically decreased and the public face a lot of problems with the interruptions to continue the developmental activities related to product manufacturing, agriculture development and services continuation. The entrepreneurs are to be encouraged more by the central and state governments with certain assurance in the way of secured returns would increase confidence and investors may bounce back to funds flow to ventures.

It is surprising that the declined exports influencing GDP has been well identified by the public and suggested the governments to encourage products and services of unique selling proposition (USP) to sell them in the international market. On the other hand, reduced imports of certain commodities such as gold and other needless goods are to be taken up by the government.

Discontinuous government overheads is completely ignored by the public which does not mean that they have little knowledge, but most of the government expenditure is on welfare schemes and developmental activities which cannot be discouraged by the public and they feel that it is highly necessary at every time and should be continued.

\section{REFERENCE}

1. Adenomon, M. and Oyejola, B. A, Impact of Agriculture and industrialization on GDP in Nigeria: Evidence from VAR and SVAR Models, Munich Personal RePEc Archive, 9 September 2013.

2. Basu, Kauirik, "In India, Black Money Makes for Bad Policy". The New York Times. 27 November 2016.

3. Ben EtimUdoh, Emmanuel Samuel, AbnerIshaku Prince, Ike Ruby Nneka And TingirTerzungwe Joshua E (2018), Effect Of Administrative Capital Expenditure On Economic Development: An Emerging Nation Outlook, Journal of Internet Banking and Commerce An open access Internet journal (http://www.icommercecentral.com) Journal of Internet Banking and Commerce, April 2018, vol. 23, no. 1.

4. Charansingh, SubhashBharadwajPemmaraju and Rohan Das, Economic Growth and Banking Credit in India, IIMB- WP 531, December 2016.

5. Dutta, Prabash K. "Demonetisation: What India gained, and lost". India Today. Retrieved 12 October 2018.

6. https://blog.saginfotech.com/gst-impact-on-gdp-india 
7. Mohammad Rafiqul Islam, MohaiminulHaque. The Success of Export and Its Impact on GDP of Bangladesh. International Journal of Investment Management and Financial Innovations. Vol. 4, No. 1, 2018, pp. 9-13.

8. MukherjiRonit, PandeyDivya. The Relationship between the Growth of Exports and Growth of Gross Domestic Product of India. International Journal of Business and Economics Research. Vol. 3, No. 3, 2014, pp. 135-139. doi: 10.11648/j.ijber.20140303.13.

9. Robinson MO, Eravwoke KE, Ukavwe A Government expenditures and economic growth: The Nigerian experience. Mediterranean Journal of Social Sciences, 2014, 5: 89-94.

10. Roy Choudhury, Arup (12 November 2016). "Demonetisation damage greater than its benefits, says KaushikBasu". Business Standard. Retrieved 12 November 2016.

11. SantoshRanganath N. and VenuGopal K, (2013), "Growth Of Insurance Sector In India - The New Horizons" Columbia International Publishing- Journal of Globalization and Business Management, 14 December 2013., Vol. 1 No. 2, doi:10.7726/jgbm.2013.1005, pp. 72-82

12. SunaKorkmaz, Impact of Bank Credits on Economic Growth and Inflation, Journal of Applied Finance \& Banking, vol. 5, no. 1, 2015, 57-69, Scienpress Ltd, 2015.

13. Samson, AA. (2013) Government spending and economic growth in Nigeria. Munich Personal RePEc Archive (MPRA) 2: 1-23.

14. Venugopal K, Rajesh B, MulugetaNegash and AschalewAdaneBrhanu

(2016) "Family Decision Making on Purchasing the Gold: A Study on The Transition of Indian Gold Imports into Economic Turmoil", Journal of Exclusive Management Science (JEMS), Volume: 5, Issue: 6, June 2016, PP: 1 - 11.

15. Venugopal K, Guntuboina Ravi Kumar L.S, Nagaraju M., Ratnalu D., "Bank Nationalisation - 44 Years Of Socio-Economic Justice In India", International Journal of Innovative Research and Practices, Forum for Intellectual Academicians and Researchers, Volume1, Issue 7(1), July 2013, PP.10-18

16. Udah, E. B. (2010): Industrial Development, Electricity Crisis, and Economic Performance in Nigeria. European Journal of Economics, Finance and Administrative Sciences. 18:105- 121. 